implante suspeito de endometriose peritoneal, a qual foi biopsiado. Somente os implantes que confirmaram o diagnóstico histológico de endometriose foram considerados no presente estudo. De acordo com o aspecto laparoscópico, as lesões foram agrupadas em: Grupo V - Lesões Vermelhas, Grupo N - Lesões Negras, Grupo B Lesões Brancas. Os parâmetros histológicos estudados foram: presença de hemossiderina no estroma, vascularização estromal, número de mitoses, presença de debris intraluminais, presença de fibrose no estroma, profundidade da lesão, característica do epitélio glandular e do estroma e relação estroma/glândula.

A análise comparativa das variáveis idade e paridade não mostrou diferença significante nos diferentes grupos de estudo. A presença de hemossiderina no estroma se mostrou equivalente nos 3 grupos. A análise da presença de vasos no estroma da lesão endometriótica que foi classificada de I a III de acordo com a quantidade, mostrou diferença significante nos 3 grupos, sendo que a vascularização exuberante (nivel III) esteve presente em 60\% das lesões vermelhas (grupo V) e 10\% nas lesões brancas (grupo B). O número de mitoses não mostrou diferença significante nos 3 grupos. Em relação à presença de debris intraluminais, houve diferença significante entre os 3 grupos, estando presente em 58,33\% das lesões negras (grupo N). A presença de tecido fibrótico na lesão endometriótica apresentou associação estatisticamente significante nos 3 grupos, sendo mais freqüente no grupo B (lesões brancas) 70,59\%.

A profundidade da lesão mostrou associação estatisticamente significante entre os grupos de estudo. As lesões vermelhas (grupo V) mostraramse superficiais em $100 \%$ dos casos. As lesões negras (grupo $\mathrm{N}$ ) apresentaram-se superficiais em $55,56 \%$, intermediárias em $38,89 \%$ e profundas em 5,56\%. As lesões brancas (grupo B) mostraramse superficiais em 28\%, intermediárias em $68 \%$ e profundas em $4 \%$.

A característica funcional do epitélio também mostrou associação estatisticamente significante nos grupos, sendo o epitélio com características secretora encontrado em $68,42 \%$ das lesões do grupo V, 15,79\% do grupo B, enquanto que o epitélio incaracterístico foi encontrado em 19,35\% do grupo V, 38,71\% do grupo $\mathrm{N}$ e $41,94 \%$ do grupo B. As características estromais mostraram associação estatisticamente significante entre os grupo de estudo, estando presente em $79,17 \%$ das lesões do grupo $\mathrm{V}, 50 \%$ do grupo $\mathrm{N}$ e $24 \%$ do grupo $\mathrm{B}$. a relação estroma/glândula não mostrou associação estatisticamente significante entre os grupos de estudo.

Das variáveis analisadas nos diferentes grupos de estudo, em seis houve associação estatisticamente significante, reforçando a teoria evolutiva da endometriose peritoneal.

Palavras-chave: Laparoscopia. Endometriose.

\title{
Transporte Eritrocitário da L-Arginina em Gestantes Normais e com Pré-Eclâmpsia
}

Autor: João Alfredo Piffero Steibel

Orientador: Prof. Dr. Carlos Eduardo Poli de Figueiredo

Dissertação apresentada ao curso de Pós-Graduação em Clínica Médica da Pontificia Universidade Católica do Rio Grande do Sul, para obtenção do Título de Mestre, em 27/1/99.

Objetivos: Estudar o transporte total da L-arginina, através da membrana celular, em eritrócitos de gestantes normais e com pré-eclâmpsia (PE). Mensurar e comparar os parâmetros cinéticos $\left(\mathrm{V}_{\max }\right.$ e $\mathrm{K}_{\mathrm{m}}$ ) do transporte de L-arginina em gestantes normais e com PE. Relacionar os parâmetros cinéticos aos dados clínicos e laboratoriais das gestantes.

Delineamento: estudo transversal, observacional e controlado.

Pacientes e Métodos: incluímos pacientes com 28 semanas ou mais de gestação que apresentavam tão somente $\mathrm{PE}$ e gestantes normais também no terceiro trimestre de gestação. O transporte eritrocitário de L-arginina foi realizado pela metodologia empregada por Hellory em 1982. A taxa de influxo foi calculada a partir da relação entre as contagens por minuto emitidas por contador $b$, volume de células e tempo de incubação a 37 graus Celsius. A capacidade máxima de transporte $\left(\mathrm{V}_{\max }\right)$ e a constante de meia saturação $\left(\mathrm{K}_{\mathrm{m}}\right)$ foram obtidas através da equação de cinética enzimática de Michaelis-Menten. Estimamos um número mínimo de 19 pacientes por grupo, com nivel de significância 
de $\alpha \leq 0,05$. A análise estatística foi feita pelo teste $t$ de Student, Mann-Whitney e coeficiente de Pearson para correlações.

Resultados: Nas 21 pacientes com PE a média do $\mathrm{V}_{\max }$ foi de $982,69 \mu \mathrm{mol} / \mathrm{L}$ de céls/h enquanto a média para as gestantes normais foi de 584,73 $\mu \mathrm{mol} / \mathrm{L}$ de céls $/ \mathrm{h}$. O $\mathrm{K}_{\mathrm{m}}$ foi de $59,31 \mu \mathrm{mol} / \mathrm{L}$ nas $\mathrm{PE}$ e de 59,46 $\mu \mathrm{mol} / \mathrm{L}$ nas normais. Houve correlação das variáveis clínicas com o $\mathrm{V}_{\max }$ e não com o $\mathrm{K}_{\mathrm{m}}$. Conclusões: o $\mathrm{V}_{\max }$ foi maior nas pacientes com $\mathrm{PE}$ quando comparada com gestantes normais. Houve correlação das variáveis clínicas com o $\mathrm{V}_{\max }$ e não com o $\mathrm{K}_{\mathrm{m}}$.

Palavras-chave: Gravidez normal. Hipertensão na gravidez, investigação e tratamento.

Expressão Endometrial das Proteinas de Membrana Reguladoras do Sistema Complemento CD59, DAF, MCP e CR1 em Mulheres Normais e Naquelas Submetidas à Hiperestimulação Ovariana

Autor: Rosana Rita N. Fonzar Marana

Orientador: Prof. Dr. Rui Alberto Ferriani

Dissertação de Mestrado, apresentada à Faculdade de Medicina de Ribeirão Preto da Universidade de São Paulo, na Área de Tocoginecologia, em 11/03/99.

Introdução: Os tecidos do trato reprodutivo expressam e sintetizam componentes do sistema complemento (SC) ao longo do ciclo menstrual, em estreita correlação com os niveis hormonais, o que sugere a necessidade de controle de sua ativação. Os ciclos submetidos à hiperestimulação ovariana podem apresentar modificações na expressão dessas proteínas em decorrência das altas concentrações hormonais.

Objetivos: Avaliar a expressão endometrial das proteínas reguladoras do $\mathrm{SC}$ ao longo do ciclo menstrual normal e de pacientes submetidas a hiperestimulação ovariana (HO) para fins de fertilização assistida e transferência de embriões (FIV-TE).

Casuística e Métodos: Foram avaliadas a expressão do CD59, DAF, MCP e CR1, no endométrio de 32 mulheres normais durante as diferentes fases do ciclo menstrual e de 10 pacientes submetidas à HO durante a fase lútea intermediária através da técnica de imuno-histoquímica.

Resultados: O CD59 como o DAF, se expressaram no endométrio durante a fase secretora, em ambos os grupos de mulheres. O CD59 teve marcação mais intensa na fase secretória intermediária enquanto que o DAF, nas fases secretória intermediária e tardia. Houve expressão da MCP no epitélio glandular em todo o ciclo menstrual, com diminuição na subfase proliferativa intermediária. O CR1 não foi detectado em nenhum dos grupos. Não houve marcação para nenhum anticorpo estudado, no estroma endometrial.

Conclusões: As proteínas reguladoras do SC, CD59, $\mathrm{DAF}$ e MCP estão presentes no endométrio humano normal e naqueles hiperestimulados, com exceção do CR1. A subfase em que o CD59 foi demonstrado sugere que o mesmo tenha grande importância durante o processo de implantação do embrião. O DAF, da mesma forma, deve contribuir para que ocorra a nidação e o início da gestação de modo adequado, através do controle do SC.

Palavras-chave: Endométrio, investigação, Ciclo menstrual.

\section{Mulheres Infectadas pelo HIV: 0 Impacto na Anticoncepção, no Comportamento Sexual e na} História Obstétrica

Autor: Jarbas Magalhães

Orientador: Prof. Dr. Paulo César Giraldo

Dissertação de Mestrado apresentada ao Curso de Pós-Graduação em Medicina, área de Tocoginecologia da Faculdade de Ciências Médicas da Universidade Estadual de Campinas, para obtenção do título de Mestre em Medicina, em 30/9/98. 